\title{
Docetaxel Regimen
}

National Cancer Institute

\section{Source}

National Cancer Institute. Docetaxel Regimen. NCI Thesaurus. Code C160024.

A chemotherapy regimen consisting of docetaxel that may be used in the treatment of bladder, gastric, cervical, head and neck, non-small cell lung, ovarian, fallopian tube, primary peritoneal, prostate, endometrial, esophageal and esophagog astric junction cancers; malignant sex cord-stromal (SCST) and malignant germ cell tumors (GCTs). 